\title{
RFID microchip internal implants: effects on grapevine histology
}

\author{
A. Luvisi*, A. Panattoni*, R. Bandinelli**, E. Rinaldelli**, M. Pagano**, B. Gini***, E. Triolo* \\ * Dipartimento di Coltivazione e Difesa delle Specie Legnose “G. Scaramuzzi”, sez. Patologia \\ Vegetale, Via del Borghetto, 80, 56124 PISA, Italy. \\ ** Dipartimento di Ortoflorofrutticoltura, Università degli Studi di Firenze, Viale delle Idee, 30, \\ 50019 Sesto Fiorentino (FI), Italy. \\ *** Vivai New Plants di Barbara Gini, Via Togliatti, 41, 56040 Cenaia (PI), Italy. \\ Abbreviations: RFID = radiofrequency identification;
}

\section{ABSTRACT}

Interesting applications for traceability in agriculture have recently been developed using radiofrequency identification (RFID) technology. A preliminary report of survival and growth in grapevine suggested pith not only as optimal microchip localization within the plant, but only continuous monitoring of performances, supported by histological observation of tissues around microchips, can validate this approach as a long-term strategy for grapevine identification. In this study, histological assays of grapevine plants are reported, considering different strategies in RFID marking. Microchip insertion after direct drilling of pith from a distal cut on rootstocks did not show any differences in tissue status compared to control, and this can be adequately correlated to an absence of effect in plant growth. Conversely, a "U" cut performed laterally on the rootstock to insert the microchip, which involved tissues from bark to pith, caused development of callus tissues, restoring transversal continuity, but with a partial loss of functionality in terms of open vessels. This phenomenon can be considered permanent damage to plant vascular function, but with limited extension.

Key words: nursery, radiofrequency identification, traceability, pith, grapevines

\section{Introduction}

Plant traceability in grapevine nurseries is closely linked to health and qualitative characteristics, and is currently reported on labels as required by European Union regulations (68/193/CEE). These traditional labels represent the only tool available for commercial grapevine identification as they contain the datasheet for the material. These labels can pose some limitations, 
for example their colour can fade and written information can be lost over time, labels can fall off or be torn, and often the space available is not sufficient to contain the information. Moreover, labels do not refer to every single plant, but rather to groups of grapevines joined by laces.

These limitations suggest that development of new, more plant-specific tools for identification, capable of containing much more data could be useful. There has been increased interest regarding traceability in agriculture, thus implementation of supporting technology for this purpose, linking all aspects of the production line, could have positive effects for food safety and for protection of the breeder's right. Interesting applications have been widely developed using radiofrequency identification (RFID) technology in animal identification systems (Artmann, 1999; Jansen and Eradus, 1999), following a reduction of technology costs (CNIPA, 2007) and worldwide spread (Das, 2005). Recently, application of this technology was studied in plants, considering Prunus spp. (Bowman, 2005), Citrus spp. (Grieco et al., 2006) and Vitis spp. (Luvisi, 2007; Triolo et al., 2007; Bandinelli et al., 2009), with different techniques and microchip allocations. However, compared to the widely described effects of RFID application in animals, little information about the impact of RFID on plant development, growth and health status is available, especially with regard to microchip insertion in plants.

A preliminary report in grapevine (Triolo et al., 2007) suggests pith as optimal microchip localization within the plant. Microchip insertion in grapevine pith can be obtained by two different procedures, and each method has its own advantages, i.e. it can be performed during grafting phase without additional wound to the plant (defined as procedure A), or with a more easily mechanized procedure (defined as procedure B). Data about the impact of microchip implantation on growth in grapevine were reported on nursery stage (Luvisi, 2007, Triolo et al., 2007) and during two years of vineyard farming (Bandinelli et al., 2009). In these reports no decrement in growth was recorded for procedure A, and limited effects were noted following procedure B. However, the microchip represents an alien item inside living tissues, and potential effects due to space occupation, materials, radiofrequency waves and wounds relative to insertion need to be evaluated before longterm predictions can be made. Thus, a histological approach could support the validation of these procedures, taking into account the differences between the methods and their impact on plant morphology.

In this paper, histological assays on grapevine plants are reported, considering different strategies in RFID marking.

\section{Materials and Methods}




\subsection{Experimental design}

The experimental trials reported were conducted at a nursery specialized in grafted-cutting productions. 4 replicates of 25 grapevine plants per treatment were established following a random layout (300 plants in total). 5 plants from each replicate were random collected for histological and growth assay.

\subsection{Plant material}

Trials involved grafted cuttings of Vitis vinifera cv. Sangiovese (clone I-SS-F9-A5-48) grafted in 2007 on rootstock 1103 Paulsen (Vitis berlandieri x Vitis rupestris), supplied by the Associazione Toscana Costitutori Viticoli (TOS.CO.VIT., San Piero a Grado, Pisa, Italy, www.toscovit.it).

\subsection{Electronic material}

Transponder glass TAG RFID were used, $2.1 \mathrm{~mm}$ diameter and $12 \mathrm{~mm}$ length, working at a frequency of $125 \mathrm{KHz}$ (InterMedia Sas, Forlì, Italy, www.RFID360.net). TAGs were electronically read by way of a 14-length identification number using a Card Flash reader connected by SD slot to palm-PC (Dell Axim X51) able to identify the microchips from $20 \mathrm{~cm}$ distance. Data recovery was performed using a palm-PC containing a database software specifically programmed using SprintDB Pro (www.kaione.com) for storing the data of each plant.

\subsection{Methods of microchip implantation}

TAGs were inserted inside pith of rootstock (average cutting length $30 \mathrm{~cm}$, average diameter $1.5 \mathrm{~cm}$ ) in April 2007, following two different procedures (Fig. 1), that are deposited for patent registration (RM2009A000271). The first one (A) involves microchip insertion after 4-cm depth direct drilling of pith from distal cut of rootstock just before omega grafting. Then, the microchip was located $3 \mathrm{~cm}$ below grafting point. The second procedure (B) were performed after omega grafting, and it consists in a "U" cut performed laterally on the rootstock $3 \mathrm{~cm}$ below the grafting point, by a designed machine by Authors (Bandinelli et al., 2009), involving tissues from bark to pith. After each procedure, the microchip was located inside the pith, and cut tissues were manually reassembled. Unmarked omega grafted plants were used as control.

\subsection{Image analysis and histological observation}

Measurements of vascular tissue area by image analysis were made on samples collected in January 2008 (two years old plants) and January 2009 (three years old plants), on fresh trunk 
sections in proximity of the microchip location (starting from $3 \mathrm{~cm}$ below graft point), at approximately mid-length of the microchip ("height 0"), $3 \mathrm{~mm}$ higher ("height 3") and $3 \mathrm{~mm}$ lower ("height -3"). In unmarked plants, sections were taken at the same height of marked ones. Vascular tissue area was calculated using software for image analysis (Cerri et al., 1993), measuring total vascular tissue area and non-necrotic vascular tissue area.

For histological observation, fresh transversal sections $(20 \mu \mathrm{m}$ thick) were made with a rotary microtome (Reichert-Jung, Autocut 2040, Osterreich) and stained with Toluidine Blue O (Sigma-Aldrich Corporation, USA); sections were immediately observed with a light microscope (Leica, Wetzlar, Germany).

\subsection{Growth assay and microchip test}

No pruning was performed during 2007, while two branches were allowed to develop during 2008. For plant growth, mean relative growth rate (MRGR) was calculate using equation reported by Kolb and Steiner (1990), with one sampling period of 90 days, calculated since shoots start growing. The dry weight was performed drying the shoots in a oven set at $100^{\circ} \mathrm{C}$ overnight, and cooling shoots in a closed plastic bag.

The RFID system was tested evaluating TAGs reliability, performing a microchip reading before sampling for histological observation.

\subsection{Data analysis}

The effects of treatments were compared, even considering differences between years of sampling, by analysis of variance in a random design. The Duncan's multiple range test at $5 \%$ level (Duncan, 1955) was calculated in order to compare treatments for functional vascular area, characterized by undamaged vessels and in which xylem rays are developed as control, and for growth parameters. Effects of treatments were expressed as functional vascular tissue area out of total $(\%)$ and MRGR $\left(\mathrm{mg} \mathrm{d}^{-1}\right)$. Data in percentage were normalized by arc sin square root transformation (Camussi et al., 1995).

\section{Results}

\subsection{Image analysis}

In Tab. 1, mean functional vascular tissue areas (\%) are reported at 3 heights in 2008 and in 2009, considering each treatment. Since 2008, no effects due to procedure A were registered compared to control considering each height. Conversely, procedure B causes a reduction in 
functional vascular tissue area in proximity to microchip and above it, whereas below microchip allocation any alteration was not observed. Anyway, non-necrotic vascular tissue area was proportionally higher in 2009 compared 2008 (Tab. 1).

With regard to procedure $\mathrm{B}$, two different macroscopic conformations were observed $\left(\mathrm{B}_{1}\right.$ and $\mathrm{B}_{2}$ ), suggesting an additional measurement for each case (Tab. 2). $\mathrm{B}_{1}$ conformation was observed in $75.0 \%$ of samples in $2008,80.0 \%$ of samples in 2009 . It was characterized by a continuous vascular ring at each considered height, while in $\mathrm{B}_{2}$ the vascular ring was discontinuous at height 0 .

$\mathrm{B}_{1}$, the most common case of wound development, was characterized by larger functional vascular tissue area than $\mathrm{B}_{2}$ at height 0 and 3, during all observed period.

\subsection{Histological observation}

Control is shown in Fig. 2. In grapevine plants marked using procedure A, enlarging vessel elements were present in all vascular bundles (Fig. 3-I). Xylem vessel elements had helical scalariform pitting depending on their developmental stage. Xylem parenchyma was present in the xylem tissue. Well-developed multiseriate rays, composed of radially elongated parenchyma in the vascular cylinder of the stem were showed. The vessels are undamaged and xylem rays are developed as control, without deformation even in proximity to microchip (Fig. 3-II). Thus, with regard to control plant, any difference in tissues development is registered in marked ones following procedure A. These observations show as procedure A did not cause any effect on vascular tissue compared to control, according to image analysis (Tab. 1).

$\mathrm{B}_{1}$ is shown in Fig. 4-B1. Referring to the vascular bundle developed after microchip insertion, xylem vessels were plugged achieving complete occlusion of their lumen (browned wound parenchyma). Moreover, a younger vascular bundle was newly developed (cicatricial parenchyma), restoring the vascular connection. In correspondence to the cut zones, callus tissue developed, joining wound margins and establishing radial continuity. That histological conformation is limited in longitudinal length to microchip presence (height 0 ), above and below which transversal section condition is similar to control.

With regard to $B_{2}$, at height 0 vascular bundle was not achieved (Fig. 4-B2), with large periderm production, permanently viewable. After the " $U$ " cut, the healthy cambium tissue starts its activity again, producing enlarged tissues, deforming the interested area into a "hook". The xylem rays and vessels are deformed due to callus production. This conformation involves up to $6 \mathrm{~mm}$ of trunk length in proximity to the centre of the microchip. 
With regard to $\mathrm{B}_{2}$, at height 3 , in which we observed a restored bundle due to the callus activity of opposing hooks (Fig. 5-I). In fact, thanks to the presence of repairing tissue observed in 2009, the wounds are covered by undifferentiated and disorganized cells (Fig. 5-II), and opposite portion of bark are merged together, as happened to cambium. Above this point, due to the restored cambium ring, xylem and phloem tissues are regularly generated, without any visible trace of wound.

\subsection{Growth assay and microchip test}

Growth of shoots did not show significant differences in marked plants by procedure A in 2007 and 2008 assay, while significant differences where registered considering procedure B in 2007 assay (Tab. 3).

Two years of farming do not compromise TAGs reliability, with $100 \%$ of readable microchips considering samples collected in 2008 and 2009.

\section{Discussions}

Image analysis of plants subjected to procedure A do not show any differences in tissues status compared to the control. Indeed, the insertion method does not cause additional wounds to the rootstock as reported by histological observations; only a portion of pith is removed. This damage in itself is insignificant due to limited functional properties of medulla. Moreover, the proximity - or contact - of the glass microchip capsule to primary xylem does not cause any alteration (Fig. 3-II). Observations of plants subjected to procedure A can be adequately correlated to an absence of effects on plant growth, according to previous studies (Bandinelli et al., 2009).

Conversely, some differences in vascular tissue area compared to control were observed in plants subjected to procedure $\mathrm{B}$, but with distinct morphological development. This insertion method is more invasive than procedure A because an additional " $U$ " wound is caused which involves all tissues between bark and pith. In any case, microchip position is the same in both procedures and no interaction of the glass capsule with primary xylem was observed. In most cases $\left(\mathrm{B}_{1}\right)$, the cut causes development of callus tissues by cambial activity, restoring transversal continuity as reported by Panattoni et al. (2001), but with a partial loss of functionality in terms of open vessels. This phenomenon can be considered as permanent, but limited, damage to plant vascular function. In a few cases $\left(\mathrm{B}_{2}\right)$, following procedure $\mathrm{B}$ there was incomplete restoration of vascular bundle, with more extensive damage. However, damage is limited in length $(6 \mathrm{~mm})$; above and below the cambium ring is restored (Fig. 5-I). Observation of procedure B seems to be 
correlated to some decrements in growth registered in plants 45 days after planting (Bandinelli et al., 2009) and confirmed in 2007 results (Tab. 3). However, 2008 growth assay did not shown differences in procedure B compared to control, according to the lower widening of necrotic area at height 0 and height 3 in 2009 compare to 2008 (Tab. 1), thanks to new xylem formation.

TAGs reliability was not compromised by insertion within plant, as observed in others woody plants (Bowman, 2005; Grieco et al., 2006).

\section{Conclusions}

RFID microchips can potentially be inserted in grapevine following procedure A with no effects, while microchip implanting by procedure B causes limited effects which are generally tolerated by the plant. Moreover, RFID microchips are totally reliable for grapevine implanting, as shown by reading test.

RFID marking is a powerful tool for traceability in agriculture, especially where specific regulations are linked to plant characteristics, i.e. genetic and health status. Keeping this in mind, grapevine could be ideal for RFID technology development.

\section{Acknowledgments}

We acknowledge the funding of our research by Associazione Toscana Costitutori Viticoli (TOS.CO.VIT.).

\section{References}

Artmann, R., 1999. Electronic identification systems: state of the art and their further development. Computers and Electronics in Agriculture 24, 5-26.

Bandinelli, R., Triolo, E., Luvisi, A., Pagano, M., Gini, B., Rinaldelli, E., 2009. Employment of radiofrequency technology (RFID) in grapevine nursery traceability. Advances in Horticultural Science 23(2), 75-80.

Bowman, K.D., 2005. Identification of woody plants with implanted microchips. HortTechnology 15(2), 352-354.

Camussi, A., Moeller, F., Ottaviano, E., Sari Gorla, M., 1995. Metodi statistici per la sperimentazione biologica. Zanichelli, Bologna.

Das, R., 2005. RFID tag sales in 2005-how many and where. IDTechEx Ltd.

Duncan, D.B., 1955. Multiple range and multiple F tests. Biometrics 11, 1-42

Cerri, S., Panattoni, A., Triolo E., 1993. Studio, progetto e sperimentazione di una procedura semiautomatica per l'analisi di alterazioni del legno in barbatelle di vite. Consiglio Nazionale Ricerche, Nota Interna B4-25, 1-24.

CNIPA, 2007. Linee guida per l'impiego dei sistemi RFId nella Pubblica Amministrazione. I Quaderni, 30 febbraio 2007, 45-47. 
Luvisi, A., 2007. Radiofrequency technology (RFID) in grapevine nursery for sector traceability. In Proc. ID WORLD International Congress 2007, CD-ROM, Milano.

Jansen, M.B., Eradus, W., 1999. Future developments on devices for animal radiofrequency identification. Computers and Electronics in Agriculture 24, 109-117.

Kolb, T.E., Steiner, K.C., 1990. Growth and biomass partitioning response of northern red oak genotypes to shading and grass root competition. For. Sci. 36, 293-303.

Grieco, P.D., Mendoliera, S., Castoro, V., Vitelli, V., Cellini, F., Agnello, A., Buccigrossi, F., Vigo, G., 2006. La tecnologia RFID per la tracciabilità e la certificazione delle produzioni vivaistiche. Rivista di Frutticoltura 10, 60-70.

Panattoni, A., Materazzi, A., Triolo, E., 2001. Origin of the infections of esca disease: hystological studies in wunded reaction zones of Vitis vinifera cv. Sangiovese. Phytopathologia Mediterranea 40, S485.

Triolo, E., Luvisi, A., Bandinelli, R., Rinaldelli, E., Pagano, M., 2007. RFID technology for improving traceability in grapevine nursery sector. Journal of Plant Pathology 89(3), 63-64. 


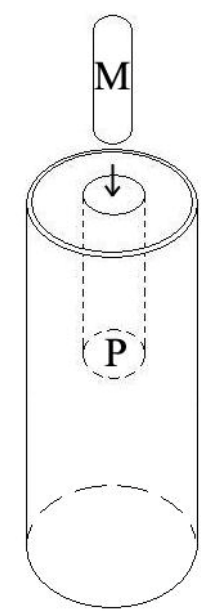

A

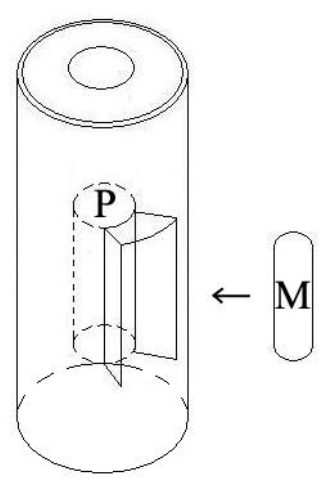

B

Figure 1. Schematization of microchip insertion: A) Procedure A; B) Procedure B; M) Microchip; P) Pith. 


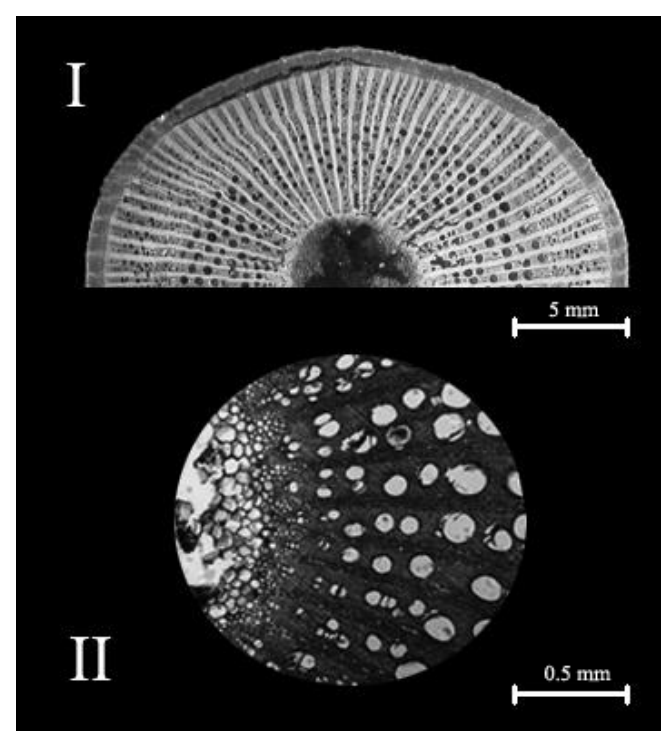

Figure 2. I) control, 1x transversal section, height 0; II) 10x, dyed, in proximity to pith. 


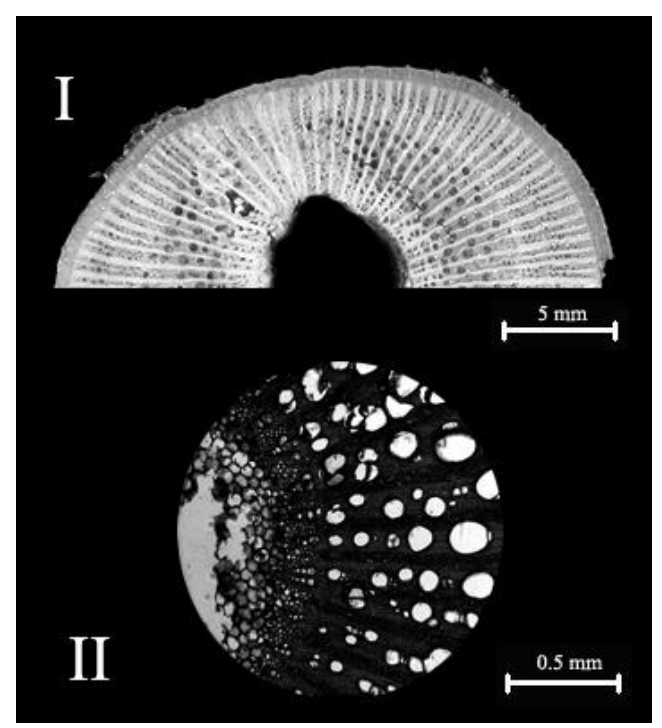

Figure 3. I) procedure A, 1x transversal section, height 0 ; II) 10x, dyed, in proximity to pith. 


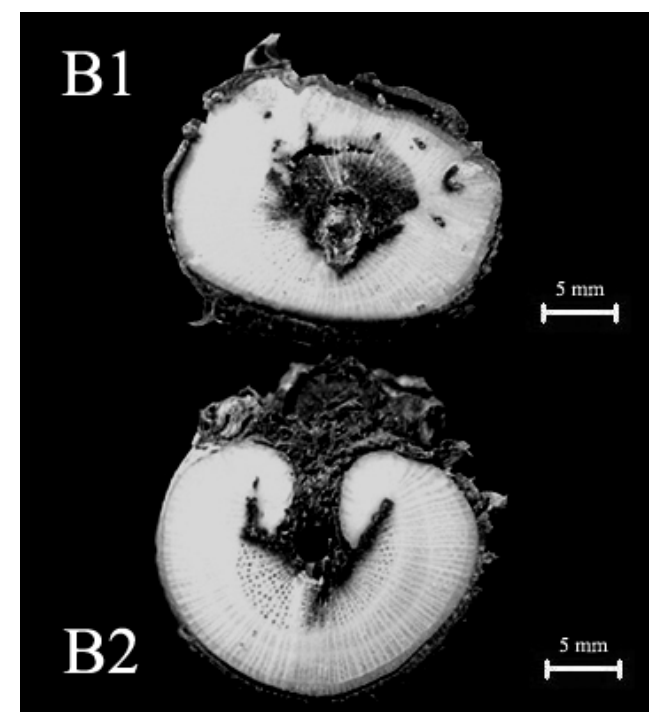

Figure 4. B1) $\mathrm{B}_{1}, 1 \mathrm{x}$ transversal section, height 0 ; $\mathrm{B} 2$ ) $\mathrm{B}_{2}, 1 \mathrm{x}$, transversal section, height 3 . 


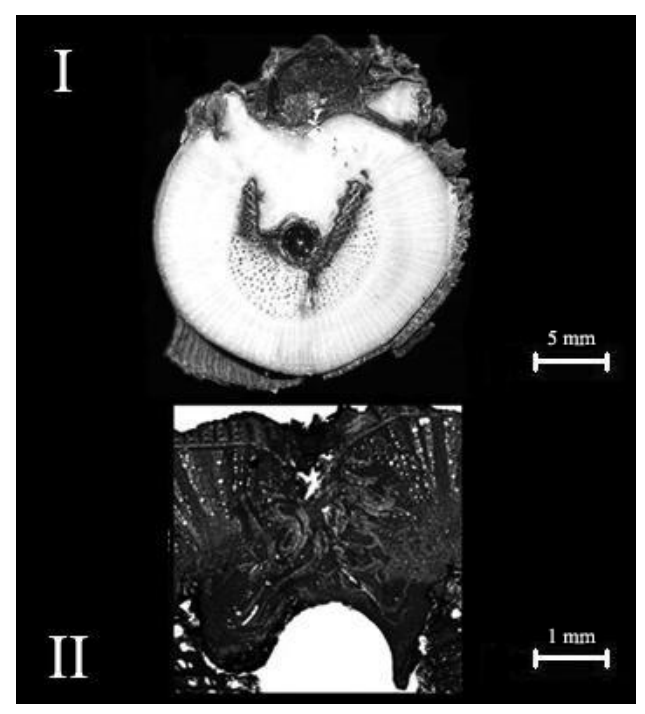

Figure 5. I) $B_{2}, 1 x$ transversal section, height 3; II) 10x, dyed, area delimited by "U" cut. 
Tab 1. Effects of implant procedures (A, B) to functional vascular tissue area (\%), in 2008 and 2009, measured at 3 heights. Mean data from 20 plants per treatment are reported.

\begin{tabular}{|c|c|c|c|c|c|c|}
\hline \multirow{3}{*}{ Procedure } & \multicolumn{6}{|c|}{ Functional vascular tissue area (\%) } \\
\hline & \multicolumn{2}{|c|}{ Height -3} & \multicolumn{2}{|c|}{ Height 0} & \multicolumn{2}{|c|}{ Height 3} \\
\hline & 2008 & 2009 & 2008 & 2009 & 2008 & 2009 \\
\hline Control & $98.8 \mathrm{a}^{*} \mathrm{~A}^{* *}$ & $99.3 \mathrm{a} \mathrm{A}$ & 99.8 a A & 99.6 a $\mathrm{A}$ & 99.4 a A & $99.6 \mathrm{a} \mathrm{A}$ \\
\hline A & 99.4 a A & 99.4 a $\mathrm{A}$ & $99.1 \mathrm{a} \mathrm{A}$ & 99.3 a $\mathrm{A}$ & 98.9 a A & $99.2 \mathrm{a} \mathrm{A}$ \\
\hline B & 99.4 a $\mathrm{A}$ & 98.6 a $\mathrm{A}$ & $70.5 \mathrm{~b} \mathrm{~B}$ & $79.4 \mathrm{~b} \mathrm{~A}$ & 89.9 b B & $95.1 \mathrm{~b} \mathrm{~A}$ \\
\hline
\end{tabular}

\footnotetext{
* Values in the same column followed by the same letter do not differ significantly according to the Duncan's multiple range test $(\mathrm{P}=0.05)$.

** Within homogeneous height, values in the same line followed by the same letter do not differ significantly according to the Duncan's multiple range test $(\mathrm{P}=0.05)$.
} 
Tab 2. Effects of implant procedure $B$ to functional vascular tissue area (\%), considering $\mathrm{B}_{1}$ and $\mathrm{B}_{2}$ development, in 2008 and 2009, measured at 3 heights. Mean data from 20 plants per treatment are reported.

\begin{tabular}{ccccccc}
\hline \multirow{2}{*}{ Development } & \multicolumn{5}{c}{ Functional vascular tissue area (\%) } \\
\cline { 2 - 6 } & 2008 & 2009 & 2008 & 2009 & 2008 & 2009 \\
\cline { 2 - 6 } & $99.3 \mathrm{a}$ & $98.5 \mathrm{a}$ & $73.0 \mathrm{a}$ & $81.0 \mathrm{a}$ & $90.2 \mathrm{a}$ & $96.3 \mathrm{a}$ \\
$\mathrm{B}_{1}$ & $99.5 \mathrm{a}$ & $98.8 \mathrm{a}$ & $64.6 \mathrm{~b}$ & $72.8 \mathrm{~b}$ & $88.7 \mathrm{~b}$ & $90.4 \mathrm{~b}$ \\
$\mathrm{~B}_{2}$ & &
\end{tabular}

\footnotetext{
* Values in the same column followed by the same letter do not differ significantly according to the Duncan's multiple range test $(\mathrm{P}=0.05)$.
} 
Tab 3. Growth of vine branches expressed mean relative growth rate (MRGR, $\mathrm{mg} \mathrm{d}^{-1}$ ) with one sampling period of 90 days, calculated since shoots start growing. Mean data from 20 plants per treatment are reported.

\begin{tabular}{cccc}
\hline \multirow{2}{*}{ Year } & \multicolumn{3}{c}{ MRGR (mg d $\left.\mathbf{~ d}^{\mathbf{1}}\right)$} \\
\cline { 2 - 4 } & Control & $\mathrm{A}$ & $\mathrm{B}$ \\
\hline 2007 & $0.107 \mathrm{a}^{*}$ & $0.108 \mathrm{a}$ & $0.098 \mathrm{~b}$ \\
2008 & $0.115 \mathrm{a}$ & $0.113 \mathrm{a}$ & $0.114 \mathrm{a}$ \\
\hline
\end{tabular}

* Values in the same line followed by the same letter do not differ significantly according to the Duncan's multiple range test $(\mathrm{P}=0.05)$. 